\title{
Overview of the Ancient Chinese Literature Appreciation from the Perspective of Thinking Aesthetics
}

\author{
Li JianQiang \\ (Sichuan Vocational and Technical College Sichuan suining 629000)
}

Keywords: Thinking aesthetics, perspective, ancient literature, language appreciation, research

\begin{abstract}
Artistic conception, that is, the atmosphere created by literary works, plays an important role in the expression of the artist's emotions and the ideological transmission of his works. Cultivating aesthetic ability plays an important role in Chinese education in middle schools. Appreciating the beauty of the language is the key to aesthetic education. Under the guidance of the theory of literary aesthetics, we analyze the language beauty of literary works and explore ways of translation of literary languages in order to enrich the understanding and study of contemporary literary language.
\end{abstract}

\section{Introduction}

The application of aesthetics in literary translation can greatly improve the quality of literary translation. Aesthetic thinking focuses on the subjectivity and creativity of the translator, aiming at highlighting the importance of readers, focusing on the beauty of the language of the literature, the beauty of the artistic conception, and the expression of beauty. Ancient literature is an important content in the field of aesthetics, which is very different from the traditional view of translation and effectively expands the translation of traditional literature. From the perspective of aesthetics, literary translation pays close attention to the intercourse and cognition among human beings and takes the function of language heavier. The language is not only a tool for transmitting the plot of literary works, but also the carrier of disseminating culture. Under the guidance of the theory of literary aesthetics, this essay analyzes the language beauty of literary works, explores the ways of translation of literary languages, and enriches the comprehension and research on literary language today.

Zhu Guangguang esthetician said: "The real literary education is not reading a lot of books and knows some literary theory and historical facts, and cultivates a pure taste." "Pure taste" is the real beauty of the perception and appreciation ability that is, aesthetic ability. Cultivating aesthetic ability plays an important role in literature education, especially in middle school Chinese education. However, "the first element of literature is language", the beautiful language loads the beauty of image, the beauty of beauty and the beauty of beauty of beauty, and the beauty of language is the key to language aesthetic education. In the teaching of Chinese, teachers should grasp the aesthetic image of the text, the beauty of the music, the beauty of the vocabulary, the beauty of the beauty of the sentence, the unique beauty of tone and so on, so as to achieve the goal of aesthetic education in Chinese teaching .

\section{The Proposed Methodology}

Aesthetic Culture of Ancient Literature. Artistic conception, that is, the atmosphere created by literary works, plays an important role in the expression of emotions and the ideological transmission of works. The poet brings to the reader an aesthetic space rich in artistic conception and rich in image through succinct conciseness and graceful exquisite language. Analyzing the artistic conception of poetry helps the translator to have a profound understanding of literary works and at the same time make the correct choice of the translated language.

One of the masterpieces by Wang Wei, a poet in the Tang Dynasty, is a collection of poems depicting the beautiful scenery and the simple life of villagers in the early evening after the early 
autumn rainy seasons. It shows the poet's longing for the seclusion of life and his delight Self-satisfied mental state. Through the depiction of natural scenery, poetry expresses personality beauty and social beauty, portraying such a beautiful and graceful picture: After the autumn rain, the mountain air is more fresh and the scenery in the country is more attractive. The bright moonlight shines through the gaps between the pines and shines on the ground, and the spring water flows over the stones in the joyous song. The return of the laundry woman talking about the sound of laughter came from the pine forest. Lotus on the water moved, indicating a fishing boat into the water. Wang Wei portrays nature's scenery through simple and graceful language, combines many images and presents the audience with a hilarious and refreshing picture. It is like a beautiful landscape painting and a sweet and soothing piece of music. It is exactly the embodiment of Wang Wei's creation features that there is a painting in the poem and a poem in the painting. In the English translation of this poem, the translator uses concise language to convey the image while maintaining the linguistic features of the poem. In the translation, the translator, in addition to translate many images truthfully, also translates the present participle form of the verb to modify the imagery and nouns so as to make the images possess the dynamic characteristics of "moving in and out of the static." The translated text gives the reader a beautiful picture of far-reaching imagination and rich imagination.

Literary works are the important carriers of the author's thoughts and emotions. Language is an intuitive expression of the author's thoughts and feelings in literary works. The readers can intuitively feel the author's thoughts and emotions through the reading of literary works. Therefore, the literary language has the characteristics of emotional beauty. Analyzing the translated language of literary works can reveal the beauty of the literary works.

The Beauty of Characters in Ancient Literature. Any literary works are based on human emotions, reflect the feelings of people, and thus inevitably need to shape the full character image. The characters in the literary works are vivid and lively under the careful design of the author, with distinctive features. Each character's language has its own characteristics. Interpreting the language of the characters in the literary works not only helps the readers to grasp the characters better, but also highlights the author's thoughts and emotions. Analyzing the language of translations in foreign novels can not only demonstrate the process of localization of the characters in the original works, but also verify whether the language of the translated images portrays and expresses the characters.

Pride and Prejudice is one of Jane Austen's novels by the famous English writer. The novel mainly talks about the love story of several daughters of Bennett family. The novel takes rural daily life as a material, and makes ironies about the artificial concept of love in the society at that time, which shows the writer's view of love. The characters in the novels are distinct, sharp in language, different in character and humorous in the language of conversation, which is exactly the result of the author's effort to shape the character through dialogue. Dialogue in the novel is full of personality, contains rich thoughts and emotions. In her novels, Madame Bennet is a superficial, snobbish, short-sighted and stupid countrywoman who does not know how to polite society and does not care about the moral cultivation of her daughters. She is bent on marrying her daughter to a good family, But always self-defeating, ridiculousness. Mr Bennet is very wise by contrast, often conversing with his wife in cynical or indifferent irony, regretting that he married such a ignorant, narrow-minded woman when she was young, Asylum. As soon as the rich bachelor, Mr. Bingley, was about to be neighbors with Mrs. Bennet, Mrs. Bennet was well aware of his basic situation and was eagerly aware of the size of her property, monthly income and singularity I hope to marry one of my daughter. She could not wait to tell her husband about the situation and hoped Mr. Bennet would come and call for more contact between the two in the future. At the beginning of the novel, Mrs. Bennet urged Mr. Bennet to start a conversation where readers can feel the vulgar and chattering character of Mrs. Bennet and the chattering linguistic style that Mr. Bennet appears to be methodical, elegant and wise. The translation of the novel in the original language of the localization of the conversion, with rich slang to Bennett's image portraits lifelike, in order to reproduce the character of the original characters, to convey the original image of the characters.

Recognize the beauty of text. The predecessors once summed up the method of making Chinese characters as "Six Books", all of which have the characteristics of images. The image-based method 
of appointment of the Six Books reflects the characteristics of Han nationality's thinking, that is, between "words" and "minds" and "images" as intermediaries. A series of Chinese characters, like a picture, express vivid meaning through vivid and graceful flowing images, creating a profound artistic conception and arousing people's infinite imagination and association, giving people a strong sense of beauty. Therefore, in the teaching of Chinese, the teachers should interpret the words and interpret the words and give the necessary image training to help them not only recognize and understand the students, cultivate their image perception ability, but also enrich the students' beauty.

Sensational voice of the music. Speech is the material shell of language, which is a kind of objective material to express voice. Harmonious rhyme, rhythmical language has beautiful music. Voice of music has a strong beauty of the power of shock, so the ancients advocated chanting, so that the sound can act on the people's hearing and emotional reaction. Chinese poetry pays special attention to the rhythm and rhyme, "chanting like a cloud and flowing water and listening to Jin Sheng Yu Zhen." Not only poetry, other literary works also pursue this artistic effect.

Xu Zhimo's "Farewell to Cambridge" is a famous text in middle school textbooks, is a reflection of the beauty of speech model. The beauty of the voice of the music is mainly manifested in the following aspects: first, arranging twists and turns; secondly, each rhyme rhythm, and rhythm by rhythm, the formation of a rhythm of the flow; third is "gently" "quiet" repeated use of overlapping characters, Rhythm light, very melodic beauty. In learning we pay attention to grasp these characteristics, we can feel the poet that enrichment, reluctantly leave the situation.

Perception of music, the beauty of speech, the teacher should explain the analysis, based on the guidance of students reading aloud, recital, with the words of Ye Shengtao should be "beauty." Such students not only understand what the author said, but also with the author's mind connected. Therefore, to enhance students 'reading ability is to cultivate students' sensitivity to the emotional color of words and to improve their ability to appreciate and perceive beauty.

The beauty of vocabulary. Sun Li's novel "Lotus Lake", is a classic in modern literature, was selected into the textbooks. When the protagonist Aquarius told his wife that he was enrolled in the Armed Forces, his wife said, "You are always very positive." Here, "total" and "very positive" show his wife's complicated feelings, complaining and reproaching Pleased to praise. A common wording, but received a wonderful artistic effect.

The beauty of language is not sublime beauty and ugly, rich vocabulary is not a pile of rhetoric, but in the language, context, give full play to the role of each word. We advocate the richness of taste vocabulary, that is, to guide students to find, chew, painstaking efforts of the author refining the euphemisms and artistic connotation of its implication, to examine the specific context of "micro-righteousness," and then get a deep sense of beauty experience.

The Value of Ancient Chinese Literature. Both Chinese ancient literature and contemporary literature belong to the same type in nature, all of which are the concentrated expression of literary form. The only difference is that the two are in different environments, and the different education accepted by the author makes the expression of the emotion slightly different. From the perspective of the world, ancient Chinese literature can be regarded as a symbol of pride and honor for our people. Liang Qi-chao once expressed his sentiments about ancient Chinese culture: "I think that for those who are Chinese, they must have the ability to appreciate the" Song of the South, "in order to create an unforgiving nation." Contemporary literature is a continuation of ancient literature, Literature is developed on the basis of ancient literature. Although knowledge comes from practice and literature comes from life, the existence of ancient literature has lightened its resistance to the development of contemporary literature and nourished the birth of innovative contemporary literature. Therefore, contemporary culture belongs to a kind of inheritance and development of traditional culture, of course, this kind of inheritance is not an unconditional and complete inheritance, but a kind of critical integration.

China is a country carrying 5,000 years of history and culture, carrying such a long history. China's achievements in literary creation have attracted worldwide attention. However, in the present society, many people think that ancient literature lacks practicality and is far from real life. Far away, so do not need to understand and learn. In fact, ancient literature is not only a reflection of the social 
environment and mood at that time, but also a proof of the historical and cultural development and a carrier of our cultural heritage.

Ancient literature encouraged people to pursue excellent spiritual character. Ancient literature emphasizes the reality of literature, which contains the ontology to encourage people to pursue truth, goodness and beauty, create excellent spiritual character. This is the most important content of contemporary literature. Ancient literary creation values personal feeling, the sensational works can truly impress the people, show enough concern for the reality of the country, family, world affairs, deeply feel the ups and downs of life. From which positive inspiration is obtained, which is also the basic spirit of ancient literature.

There is something in ancient literature that is highly targeted and enriched in content. Literature includes content and form two parts, while the material thing mainly refers to the content. The content of the article is the main object to be conveyed by the whole literary work. If nothing is said, the reader will feel unintelligible. Therefore, the contents of literary works need to enrich the material to fill in the works, the most fully embodied in ancient literary works is quoted allusions.

Culture is only a superficial meaning. In essence, the final purpose of cultural existence is to make people gain some insight just as Meng Jianwei put forward the idea of "absorbing all human development and cultural innovation in human culture Elements, and the process of education into cultural education process "the same. The impact of the development of ancient literature on human values and personality is still very important. To a certain extent, literature can be called humanity. Ancient literature is the author's description of the society and his feelings about this society.

\section{Conclusion}

The value of ancient literature and its influence are from the ancient to the present, not only have an impact on the development of contemporary literature, but also affect the contemporary concept of educating people. Against the backdrop of building a powerhouse for culture and building a harmonious society, ancient literature has given the value of the times and has become a cultural source for building a modernized nation. We should establish the awareness of attaching importance to ancient literature and give full play to the value of ancient literature in the present age. Analyzing literary language from the perspective of literary aesthetics can effectively interpret its creative method and connotation, and provide more perspectives for understanding literary language. Any literary works are based on human emotions, reflect the feelings of people, and thus inevitably need to shape the full character image. The influence of ancient literature has not been extended to the cultural aspect so far, but also extended to the shaping of human spiritual character and its impact on human values. If we want to give full play to the value of ancient literature, we should make a thorough analysis of ancient literature, interpret the works based on the social environment at that time, and induce readers and writers to have emotional resonance.

\section{References}

[1]. Wrigley, C. and Straker, K., 2017. Design thinking pedagogy: The educational design ladder. Innovations in Education and Teaching International, 54(4), pp.374-385.

[2]. Bowen, J.P., Giannini, T. and Polmeer, G., 2017, July. Coded communication: digital senses and aesthetics, merging art and life. In Proceedings of the conference on Electronic Visualisation and the Arts (pp. 1-8). BCS Learning \& Development Ltd..

[3]. Kelly, B.L. and Wodda, A., 2017. Composing an aesthetics of performance pedagogy. Groupwork, 26(2), pp.33-50.

[4]. Johannes, P.F., 2017. An Educational Perspective and a Poststructural Position on Everyday Aesthetics and the Creation of Meaning. 
[5]. Volle, E., 2017. Associative and controlled cognition in divergent thinking: theoretical, experimental, neuroimaging evidence, and new directions. The Cambridge handbook of the neuroscience of creativity. New York, NY: Cambridge University Press. 